\title{
HUBUNGAN KEPEMILIKAN ASURANSI KESEHATAN DENGAN \\ PENGGUNAAN OBAT RASIONAL (POR) PADA PASIEN SWAMEDIKASI
}

\section{(THE RELATIONSHIP OF OWNERSHIP HEALTH INSURANCE WITH USES RATIONAL DRUG (POR) IN SELF MEDICATION PATIENT)}

\author{
PUTU EKA ARIMBAWA*• \\ *Prodi Farmasi Klinis, Institut IImu Kesehatan Medika Persada Bali, Denpasar-Bali
}

\begin{abstract}
Abstrak: Kepemilikan asuransi kesehatan (pemerintah atau swasta) merupakan jaminan kesehatan masyarakat agar dapat menjangkau pelayanan kesehatan terutama dalam penggunaan obat rasional (POR) khususnya swamedikasi (pengobatan sendiri). Tujuan Penelitian ini adalah untuk mengetahui hubungan kepemilikan asuransi kesehatan dengan penggunaan obat rasional (POR) pada pasien swamedikasi. Penelitian ini dilakukan dengan desain survey cross sectional. Penelitian menggunakan kuesioner sebagai alat pengumpulan data. Teknik sampling yang digunakan adalah purposive sampling. Jumlah sampel yang digunakan sebanyak 97 pasien yang melakukan pengobatan swamedikasi yang di ambil di 30 apotek di Kota Denpasar. Analisis data menggunakan uji statistika multivariat binary logistik. Hasil penelitian menunjukan bahwa variabel pendidikan $(\mathrm{p}=0.04 ; \mathrm{OR}=2.37 ; \mathrm{CI}=1.02-5.52)$ dan kepemilikan asuransi kesehatan $(\mathrm{p}=0.04 ; \mathrm{OR}=2.77 ; \mathrm{CI}=1.01-7.53)$ memiliki hubungan yang signifikan dengan POR pada pasien swamedikasi. Sedangkan variabel lainya seperti jenis kelamin, pernikahan, pekerjaan, dan umur tidak memberikan hubungan yang signifikan ( $>0.05)$. Kepemilikan asuransi oleh pasien akan dapat meningkatkan pemahaman POR dalam swamedikasi terutama memberikan pengetahuan kepada pasien mengenai pengobatan, mengurangi pembiayaan, dan menciptakan kesejahteraan pasien.
\end{abstract}

Kata Kunci: asuransi kesehatan, POR, swamedikasi

\begin{abstract}
Ownership of health insurance (government or private) is a public health insurance in order to reach health services, and the use of rational drugs (POR) in self-medication. The purpose of study was to determine the relationship of health insurance ownership with rational drug use (POR) self-medication in patients. This research was conducted by cross sectional survey design. The study use questionnaires as a means of data collection. The sampling technique is used purposive sampling. The number of samples are used 97 patient and taken at 30 pharmacies in Denpasar City. Data analysis is used multivariate binary logistic statistic test. The results showed that the educational variables $(\mathrm{p}=0.04 ; \mathrm{OR}=2.37 ; \mathrm{CI}=1.02-5.52)$ and health insurance ownership $(\mathrm{p}=0.04 ; \mathrm{OR}=2.77 ; \mathrm{CI}=1.01-7.53)$ had significant association with POR in self-medicating patients. While other variables such as gender, marriage, occupation, and age do not provide a significant relationship ( $p>0.05$ ). Insurance health ownership by the patient will be able to improve the understanding of POR in self-medication primarily provide patient knowledge about treatment, reduce financing, and create patient welfare
\end{abstract}

Key Word: health insurance, POR, self-medication

\section{PENDAHULUAN}

Asuransi kesehatan merupakan jaminan mengatasi risiko atas pembiayaan dan perawatan kesehatan. Kepemilikan asuransi kesehatan (pemerintah atau swasta) merupakan jaminan kesehatan kepada masyarakat agar dapat menjangkau fasilitas pelayanan kesehatan.

Menurut hasil survey Kemenkes jaminan kesehatan yang dimiliki oleh penduduk (termasuk seluruh penduduk miskin) yang terealisasi sebesar 76,8\% (Kemenkes, 2013). Menurut Pusat Pengelolaan Risiko Fiskal Badan kebijakan Fiskal masyarakat yang belum memiliki jaminan kesehatan sebesar 37 \% (Pusat Pengelolaan Fiskal BKF, 2013). Selain itu juga menurut penelitian. Data Sistem Monitoring dan Evaluasi Dewan Jaminan Sosial Nasional (Sismonev DJSN) di September 2017, menunjukkan jumlah peserta Jaminan Kesehatan Nasional-Kartu Indonesia

\footnotetext{
- Author correspondence. e-mail: eka_apoteker@yahoo.co.id
} 
Sehat (JKNKIS) baru mencapai 71,3\%. Artinya, masih terdapat $28,7 \%$ yang belum memiliki jaminan kesehatan (Sismonev, 2017).

Banyaknya masyarakat yang belum memiliki asuransi kesehatan akan dapat menyebabkan peningkatan pembiayaan kesehatan khususnya dalam bidang pengobatan, sehingga menyebabkan penggunaan obat tidak rasional. Penggunaan obat rasional (POR) adalah pasien menerima obat yang sesuai dengan kebutuhannya, untuk periode waktu yang sesuai dan dengan harga yang paling murah (WHO Conference, 1985). Pengunaan obat di masyarakat untuk kesembuhan penyakit sangat tinggi terutama dalam hal swamedikasi (pengobatan sendiri). Riskedas tahun 2013 juga mencatat sejumlah 35,2\% rumah tangga di Indonesia menyimpan obat untuk swamedikasi (Badan Penelitian dan Pengembangan Kesehatan, 2013). Menurut hasil data penelitian menyatakan penggunaan obat tidak rasional mencapai lebih dari 50\% di masyarakat (WHO, 2002). Menurut hasil penelitian di Kota Penyabungan didapatkan data bahwa Penggunaan obat swamedikasi 59,4\% rasional dan 40,6\% tidak rasional (Harahap et al., 2017).

Hasil data menunjukkan masih adanya masyarakat atau pasien yang belum memiliki asuransi kesehatan dan jumlah pengobatan swamedikasi yang tidak rasional masih tergolong cukup tinggi, maka membuat peneliti tertarik melihat hubungan kepemilikan asuransi kesehatan dengan POR pada pasien swamedikasi.

\section{METODE PENELITIAN}

Penelitian ini merupakan penelitian korelasi. Penelitian dilakukan dengan desain survei cross-sectional dan mengambil sampel pasien yang melakukan pengobatan sendiri (swamedikasi) di 30 apotek Kota Denpasar antara bulan November-Desember 2017, dengan wawancara berdasarkan kuesioner. Teknik sampling yang digunakan adalah purposive sampling. Sampel yang digunakan sebanyak:

Keterangan:

$$
\begin{aligned}
\mathrm{n} & =\frac{z_{1 \cdot \pi / s}^{2} \mathrm{P}(1-\mathrm{P})}{\mathrm{d}^{2}} \\
& =\frac{(1,95)^{2} 0,5(1-0,5)}{0,1^{2}} \\
& =97 \text { sampel }
\end{aligned}
$$

$\mathrm{n} \quad=$ Sampel

$\mathrm{P} \quad=$ Peluang

$\mathrm{d} \quad=$ Limit error atau presisi absolut

$\mathrm{Z}^{2}{ }_{1-\alpha / 2}=$ Derajat kepercayaan
Jadi sampel digunakan sebanyak 97 pasien,

Kriteria inklusi penelitian pasien berumur

18-60 tahun, memilih pengobatan swamedikasi, pernah melakukan swamedikasi di apotek minimal sebanyak 5 kali. Kriteria Ekslusi penelitian ini masyarakat yang memilih pengobatan tradisional sebagai alternatif berobat, dan pasien berobat dengan resep (rawat jalan).

\section{HASIL DAN PEMBAHASAN}

\section{Hasil Uji Normalitas}

Hasil uji normalitas variabel yang akan di uji dapat dilihat pada tabel 1 .

Tabel 1. Uji Normalitas

\begin{tabular}{lc}
\hline \multicolumn{1}{c}{ Variabel } & p \\
\hline Jenis kelamin & 0.0001 \\
Status Pernikahan & 0.0001 \\
Pendidikan & 0.0001 \\
Pekerjaan & 0.0001 \\
Umur & 0.0001 \\
Kepemilikan Asuransi & 0.0001 \\
POR swamedikasi & 0.005 \\
\hline
\end{tabular}

Hasil uji normalitas didapatkan semua variable $\mathrm{P}<0.05$ sehingga perlu dilakukan uji nonparametik tes.

\section{Hasil Uji Karakterisitik Sosial-Demografi}

Hasil karakterisitik pasien dapat dilihat pada tabel 1. Sebagian besar pasien berjenis kelamin perempuan $(61.9 \%)$, sudah menikah (69.2\%), memiliki tingkat pendidikan kuliah paling banyak $(69.2 \%)$, bekerja $(60.6 \%)$, paling banyak berumur dengan rentang 18-40 tahun (83.5\%) dan memiliki asuransi kesehatan sebesar $76,3 \%$ serta pasien yang paham POR sebesar $55,7 \%$.

Tabel 2. Variabel Sosial-Demografi

\begin{tabular}{lll}
\hline $\begin{array}{c}\text { Variabel } \\
\text { Sosial-demografi }\end{array}$ & F & \% \\
\hline Jenis kelamin & & \\
Perempuan & 60 & 61.9 \\
$\quad$ Laki & 37 & 38.1 \\
Status Pernikahan & & \\
$\quad$ Tidak Menikah & 30 & 30.8 \\
$\quad$ Menikah & 67 & 69.2 \\
Pendidikan & & \\
$\quad$ SD/SMP/SMA & 46 & 47.1 \\
Kuliah & 51 & 52.9
\end{tabular}




\begin{tabular}{lll}
\hline \multicolumn{1}{c}{ Variabel } & F & $\%$ \\
\hline Sosial-demografi & & \\
\hline Pekerjaan & 24 & 23.1 \\
$\quad$ Tidak Bekerja & 73 & 60.6 \\
Bekerja & & \\
Umur & 81 & 83.5 \\
$\quad 18-40$ & 16 & 16.5 \\
$\quad 41-60$ & & \\
Kepemilikan Asuransi & 23 & 23.7 \\
$\quad$ Tidak & 74 & 76.3 \\
$\quad$ Ya & & \\
POR swamedikasi & 43 & 44.3 \\
$\quad$ Tidak rasional & 54 & 55.7 \\
$\quad$ Rasional & & \\
* $\boldsymbol{f}=$ Frekuensi, \%=presentase &
\end{tabular}

\section{Hasil Uji Multivariate Binary Logistik}

Hasil uji multivariat binary logistik dapat dilihat pada tabel 3 antara variabel sosio-demografi (jenis kelamin, umur, status perkawinan, pendidikan, dan pekerjaan) dan kepemilikan asuransi kesehatan dengan POR swamedikasi. Hasilnya menunjukkan variabel pendidikan dan kepemilikan asuransi kesehatan berhubungan signifikan secara statistik. Hasil penelitian ini mengenai variabel pendidikan dengan POR pada pasien swamedikasi memiliki hubungan yang signifikan karena tingkat pendidikan tinggi tidak mudah terpengaruh dengan iklan obat di media dan lebih banyak membaca label pada kemasan obat sebelum mengkonsumsi obat. Mereka juga lebih sering menggunakan obat modern dibandingkan dengan obat tradisional, dengan demikian akan mengurangi risiko interaksi antara obat modern dengan obat tradisional jika dikonsumsi secara bersamaan (Kristina et al., 2008)

Tabel 3. Uji Multivariat binary logistic

\begin{tabular}{lcccc}
\hline \multirow{2}{*}{ Variabel Independen } & \multirow{2}{*}{ OR } & \multirow{2}{*}{} & \multicolumn{2}{c}{ CI 95\% } \\
\cline { 4 - 5 } & & & Batas bawah & Batas atas \\
\hline Jenis Kelamin & 0.94 & 0.90 & 0.38 & 2.31 \\
Pernikahan & 0.57 & $0.04^{*}$ & 0.22 & 1.48 \\
Pendidikan & 2.37 & 0.52 & 1.02 & 5.52 \\
Pekerjaan & 1.40 & 0.95 & 0.49 & 4.00 \\
Umur & 1.03 & $0.04^{*}$ & 0.30 & 3.50 \\
Kepemilikan Asuransi & 2.77 & & 1.01 & 7.53 \\
\hline
\end{tabular}

*Signifikan $P<0.05 ;$ CI=confidence interval

Hasil penelitian ini sejalan dengan beberapa penelitian yang dilakukan yang menyatakan bahwa responden berpendidikan tinggi lebih banyak yang melakukan pengobatan sendiri secara rasional dan tingkat pendidikan mempengaruhi pengobatan sendiri yang aman, tepat, dan rasional. Semakin tinggi tingkat pendidikan seseorang, semakin rasional dan berhati-hati dalam memilih obat untuk pengobatan sendiri (Figueras et al., 2000) (Dharmasari, 2003).

Hasil penelitian ini mengenai kepemilikan asuransi kesehatan dengan POR pada pasien swamedikasi sejalan dengan penelitian di Kabupaten Sleman dimana menunjukkan kepemilikan asuransi $(\mathrm{OR}=$ $1,84, \quad \mathrm{p}<0,05, \mathrm{CI}=1,184-2,184)$ merupakan faktor yang paling berhubungan dengan perilaku pasien geriatri melakukan swamedikasi di apotek (Supadmi, 2013). Hasil penelitian mengenai kebijakan pembayaran dan pembayaran bersama menggunakan asuransi pharmaceutical dapat mengurangi penggunaan obat-obatan dan mengurangi pengeluaran obat-obatan (Luiza et al., 2015). Pemantauan dan penggunaan informasi yang dikumpulkan untuk mengembangkan, menerapkan dan mengevaluasi strategi untuk asuransi mengubah perilaku penggunaan obat yang tidak tepat sangat penting bagi keberhasilan POR (Vijay Thawani, 2010).

Hasil penelitian di Cina menunjukkan Setelah penerapan NEMP dalam asuransi (The National Essential Medicines), rata-rata jumlah obat per resep dan biaya rata-rata per resep menurun secara signifikan (Jianqian et al., 2018). Hasil penelitian lain juga menunjukkan rata-rata jumlah penggunaan obat menurun dari 3,64 menjadi 3,46 ( $\mathrm{p}<0,01$ ) antara tahun 2009 dan 2010 dan Persentase obat yang digunakan dari Daftar Obat Esensial meningkat setelah penerapan asuransi ( $p$ $<0,01)$. Sehingga asuransi secara efektif memperbaiki penggunaan obat-obatan rasional 
di China (Song et al., 2014). Penelitian lain juga menyebutkan asuransi dan POR harus ditekankan di pelayanan kesehatan. Konsep pengobatan esensial juga relevan dengan program kesehatan lainnya dan hasilnya tidak hanya dalam penggunaan sumber daya yang lebih baik tetapi juga dalam praktik pengobatan yang lebih baik seperti terapi yang baik dan mengurangi efek samping obatobatan, dan menghemat biaya kesehatan teurtama dalam pengobatan sendiri (Kar et al., 2010)

\section{SIMPULAN}

Kepemilikan asuransi kesehatan dapat meningkatkan pemahaman POR dalam swamedikasi pasien terutama dalam hal pengobatan, mengurangi pembiayaan, dan menciptakan kesejahteraan pasien.

\section{UCAPAN TERIMA KASIH}

Ucapan terima kasih diberikan semua pihak yang membantu dalam penyelesaian jurnal ini terutama kepada apoteker Kota Denpasar yang sudah memberikan ijin di apoteknya sebagai tempat pengambilan data penelitian ini.

\section{DAFTAR PUSTAKA}

Badan Penelitian dan Pengembangan Kesehatan (2013) 'Riset Kesehatan Dasar (RISKESDAS) 2013', Laporan Nasional 2013, pp. 1-384. Desember 2013.

Dharmasari (2003) Faktor-Faktor yang Berhubungan dengan Perilaku Pengobatan Sendiri yang Aman, Tepat dan Rasional pada Masyarakat Kota Bandar Lampung Tahun 2003. Available at: http:// www. digilib.ui ac.id.

Figueras, A., Caamano, F. and Gestal-Otero, J. (2000) Sociodemographic Factors Related To Selfmedication. Available at: http://ingentaconnect.com.

Harahap, N. A., Khairunisa and Tanuwijaya, J. (2017) Tingkat Pengetahuan Pasien dan Rasionalitas Swamedikasi di Tiga Apotek Kota Panyabungan', Jurnal Sains Farmasi \& Klinis, 3(May), pp. 186-192.

Jianqian, C., Jiangyi, G., Hua, Z., Huanghui, C. and Zhenchun, W. (2018) The Impact Of The National Essential Medicines Policy On Rational Drug Use In Primary Care Institutions In Jiangsu Province of China. Available at:https://www.ncbi.nlm.nih.gov/pmc/a rticles/PMC5756597/.

Kar, S. S., Pradhan, H. S. and Mohanta, G. P. (2010) Concept Of Essential Medicines And Rational Use In Public Health. Available at: https:// www.ncbi.nlm.nih.gov/pmc/articles/P MC2888334/.

Kemenkes (2013) Laporan Akuntabilitas Kinerja Kementerian Kesehatan Tahun 2013. Jakarta.

Kristina, S., Prabandari, Y. S. and Sudjaswadi, R. (2008) Perilaku Pengobatan Sendiri Yang Rasional Pada Masyarakat Kecamatan Depok dan Cangkringan Kabupaten Sleman, Majalah Farmasi Indonesia, 19(June), pp. 32-40.

Luiza, Chaves, Silva, Emmerick, Chaves, Araújo, F. de, Moraes and Oxman (2015) Pharmaceutical Policies: Effects Of Cap And Co-Payment On Rational Use of Medicines. Available at:https://www.ncbi.nlm.nih.gov/pubm ed/25966337.

Pusat Pengelolaan Fiskal BKF (2013) Menyambut Era Baru Jaminan Sosial. Jakarta: Pusat Pengelolaan Resiko Fiskal.

Sismonev (2017) Dewan Jaminan Sosial Nasional Sistem Monitoring Terpadu. Available at: http:// www. sismonev. djsn.go.id.

Song, Y., Bian, Y., Petzold, M., Li, L. and 
Aitian Yin (2014) The Impact Of China's National Essential Medicine System On Improving Rational Drug Use In Primary Health Care Facilities: An Empirical Study In Four Provinces. Available at: https:// www.ncbi.nlm.nih.gov/pmc/articles/P MC4213512/.

Supadmi, W. (2013) 'Gambaran Pasien Geriatri Melakukan Swamedikasi Di Kabupaten Sleman', Pharmaciana, 3(2), pp. 4550 .
Vijay Thawani (2010) Rational Use of Medicines: Achievements And Challenges. Available at: https:/ /www.ncbi.nlm.nih.gov/pmc/articles/P MC2907015/.

WHO (2002) 'Promoting Rational Use of Medicines: Core Components', p. 6. Available at: http:// apps.who.int/ medicinedocs/pdf/h3011e/h3011e.pdf

WHO Conference, R. of the (1985) 'The rational use of drugs', (November), pp. 25-29. 